\title{
Protocolos de produção in vitro de embriões na raça Gir
}

\author{
[In vitro embryo production protocols in Gir breed] \\ A.A. $\operatorname{Ramos}^{1,2}$, A.M. Ferreira ${ }^{2}$, W.F. Sá ${ }^{2}$, L.S.A. Camargo $^{2}$, J.H.M. Viana ${ }^{2}$, M.R.J.M. Henry ${ }^{3}$ \\ ${ }^{1}$ Empresa de Pesquisa Agropecuária de Minas Gerais \\ Rua Tenente Luiz de Freitas, 116 \\ 36045-560 - Juiz de Fora, MG \\ ${ }^{2}$ Embrapa Gado de Leite - Juiz de Fora, MG \\ ${ }^{3}$ Escola de Veterinária - UFMG - Belo Horizonte, MG
}

\begin{abstract}
RESUMO
Avaliaram-se os efeitos de dois protocolos de punção folicular na quantidade/qualidade dos oócitos e na produção in vitro de embriões, em vacas da raça Gir, não-lactantes. O ciclo estral foi sincronizado com cloprostenol e ao longo do experimento os animais receberam implantes auriculares de norgestomet, renovados a cada 14 dias. Os animais foram submetidos aos protocolos I (sem estimulação hormonal, com punção folicular duas vezes/semana) e II (pré-tratamento com 250 UI de FSH em doses decrescentes, três dias antes da punção folicular). Os oócitos recuperados foram levados ao laboratório em meio TALP-Hepes e submetidos à maturação. Na fecundação in vitro utilizou-se sêmen de touro Gir, previamente capacitado. Após 22 horas de fecundação, os prováveis zigotos foram co-cultivados com células da granulosa em CR2aa acrescido de $10 \%$ de soro fetal bovino. A taxa de clivagem foi avaliada 72 horas pós-fecundação e a de blastocisto 192 horas pós-fecundação. O número total de folículos foi maior $(\mathrm{P}<0,05)$ no protocolo II, assim como o número de folículos grandes e médios $(\mathrm{P}<0,05)$ e o diâmetro do maior folículo $(\mathrm{P}<0,05)$, sendo o número de folículos pequenos $(\mathrm{P}<0,05)$ menor. $\mathrm{O}$ total de oócitos recuperados por sessão não foi diferente entre os protocolos I e II ( $P>0,05)$. O número de oócitos de grau I e a taxa de clivagem foram maiores $(\mathrm{P}<0,05)$ e o número de degenerados menor protocolo II. A préestimulação ovariana com FSH pode melhorar a qualidade e a taxa de clivagem dos oócitos recuperados por punção folicular em animais Gir.
\end{abstract}

Palavras-chave: bovino, Gir, embrião in vitro, punção folicular, FSH

\begin{abstract}
The effect of two ovum pick-up protocols on amount/quality of oocytes retrived and on in vitro embryo production of Gyr cows was evaluated in non-lactating cycling cows with good body and reproductive conditions. Estrous cycles were synchronized with cloprostenol. During the experiment, animals received norgestomet ear implants, replaced every 14 days. Animals were submitted to protocol I (without hormonal estimulation) and protocol II (pre-stimulation with 250 IU of FSH three days before aspiration). Recovered oocytes were transported in Talp-Hepes to the laboratory, classified and maturated. Twenty two hours after fertilization, presumptive zygotes were co-culture with granulosa cells in CR2aa supplemented with $10 \%$ of fetal calf serum. Cleavage rate was assessed at 72 hours postfertilization, and blastocyst production 192 hours post-fertilization. The total number of follicles, the number of large and medium follicles and the diameter of the largest follicle were higher $(P<0.05)$ in protocol II, and the number of small follicles $(P<0.05)$ was lower than in protocol I. No difference between protocols I and II was observed for oocytes recovered per aspiration section $(P>0.05)$. The number of grade I oocytes and cleavage rate were higher $(P<0.05)$ in protocol II and the number of
\end{abstract}

Recebido para publicação em 19 de abril de 2004

Aceito em 24 de novembro de 2005

E-mail: aleramos@cnpgl.embrapa.br 
degenerated oocytes was lower $(P<0.05)$. The pre-stimulation with FSH can improve the quality and cleavage rate of oocytes recovered by ovum pick-up in zebu animals.

Keywords: bovine, Gyr, in vitro embryo, ovum pick-up, FSH

\section{INTRODUÇ̃̃O}

Oócitos de boa qualidade, com boas características morfológicas e de desenvolvimento, são o primeiro requisito para o sucesso da produção in vitro de embriões (PIVE) (Seneda et al., 2001). O tamanho do folículo de origem e a extensão e integridade das células do cumulus influenciam a competência oocitária (Fair et al., 1995). Folículos maiores (6mm) contêm oócitos com maior potencial para tornarem-se blastocisto, enquanto folículos pequenos $(<3 \mathrm{~mm})$ contêm oócitos incompetentes (Pavlok et al., 1992).

Os oócitos recuperados sem estimulação da doadora e com freqüência de punção de uma vez/semana têm qualidade inferior aos oócitos coletados duas vezes/semana (Goodhand et al., 1999). Em doadoras gonadotropina-estimuladas, punções foliculares realizadas uma vez por semana são mais eficientes que aquelas realizadas em intervalos menores (duas vezes/semana), sendo tão eficientes quanto um regime de duas punções semanais sem estimulação prévia.

Protocolos de punção folicular utilizando préestimulação com FSH resultam em maior número de folículos viáveis a serem puncionados (Gibbons et al., 1997) e diminui a quantidade de folículos atrésicos (Sirard et al., 1999). Além disso, a administração de FSH melhora a qualidade do oócitos recuperados e aumenta à percentagem de embriões transferíveis (Goodhand et al., 1999; 2000). Tem-se sugerido que o FSH seja mais eficiente em doadoras com pouca resposta na transferência de embriões e na punção folicular guiada por ultra-som (Looney et al., 1994).

Relata-se que a superovulação pode reduzir a capacidade de desenvolvimento dos embriões. Alterações na maturação citoplasmática e nuclear do oócito podem ocorrer em animais superovulados, influenciando assim a competência de desenvolvimento dos mesmos, possivelmente por acelerar a fase de crescimento do folículo, ficando o oócito sem tempo suficiente para adquirir competência (Blondin et al., 1996).

Animais das raças zebuínas apresentam menores taxas de recuperação de oócitos e, em conseqüência, menor quantidade de embriões produzidos in vitro (Faber et al., 2003). Protocolos que utilizem superestimulação hormonal antes do início das sessões de punção folicular podem aumentar o número de oócitos colhidos in vivo. Entretanto, pouco se sabe sobre a reposta de vacas zebu à terapia gonadotrófica e qualidade dos oócitos recuperados posteriormente. Considerando-se a importância da raça Gir para a pecuária leiteira nos trópicos, este experimento teve o objetivo de avaliar, em vacas Gir, a utilização de dois protocolos, que tenham apresentado melhores resultados, em animais europeus, nas taxas de recuperação de oócitos, clivagem e produção in vitro de embriões (punções duas vezes/semana sem estimulação hormonal e punção uma vez/semana com pré-estimulação hormonal).

\section{MATERIAL E MÉTODOS}

O experimento foi realizado no período de agosto de 2001 a março de 2002. Foram utilizadas vacas $(\mathrm{n}=15)$ da raça Gir, multíparas, não-lactantes, com escore corporal entre 3 e 4 , sendo $1=$ muito magra e $5=$ gorda, e que apresentaram dois ciclos estrais normais antes do início do experimento. Os animais receberam uma aplicação intramuscular de $0,5 \mathrm{mg}$ de cloprostenol $^{1}$ e implantes auriculares contendo $3 \mathrm{mg}$ de norgestomet ${ }^{2}$ no início do experimento (dia 0), renovados a cada 14 dias. Os animais foram mantidos em pasto, ao longo do experimento. Após três dias (dia 3), os animais foram submetidos aos seguintes protocolos $(\mathrm{P})$ : PI- punção folicular duas vezes por semana (dias 3 e 6) sem estimulação hormonal e PII- punção folicular uma vez por semana (dia 6), após

\footnotetext{
${ }^{1}$ Ciosin ${ }^{\circledR}$, Coopers

${ }^{2}$ Crestar ${ }^{\circledR}$, Intervet
} 
tratamento com 250UI de hormônio folículo estimulante $^{3}$, em seis aplicações em doses decrescentes $(75,50,50,25,25$ e 25 UI) administrado em intervalos de 12 horas nos três dias precedentes (dias 3 a 5) a cada sessão de punção (Freitas et al., 1999).

Os animais, cinco de cada vez, foram submetidos inicialmente ao PI em duas repetições e, posteriormente, ao PII por duas vezes, com o objetivo de avaliar como o mesmo grupo de animais respondia a diferentes protocolos de punção folicular.

As punções foliculares foram realizadas por um mesmo técnico, utilizando-se um aparelho de ultra-sonografia equipado com transdutor setorial intravaginal de $5 / 7,5 \mathrm{MHz}$ e um dispositivo guia para punção folicular. Folículos com diâmetro superior a $3 \mathrm{~mm}$ foram identificados, mensurados e puncionados utilizando-se agulhas $19 \mathrm{G}$ e uma pressão de vácuo de $80 \mathrm{mmHg}$, correspondendo a um fluxo de $14 \mathrm{ml}$ de água/min. O líquido folicular foi inicialmente recuperado em tubos plásticos de $50 \mathrm{ml}$ (Falcon), contendo $15 \mathrm{ml}$ de DPBS acrescido de $10 \%$ de soro fetal bovino (SFB) e 100UI de heparina sódica $4 / \mathrm{ml}$, sendo posteriormente os oócitos separados em um filtro de coleta de embriões com malha de $80 \mu$ (Millipore). Os complexos cumulus-oócito recuperados foram transferidos para placas de cultivo contendo PBS (Whittingam, 1971) acrescido de $10 \%$ de $\mathrm{SFB}$ a $37^{\circ} \mathrm{C}$ e avaliados, por um mesmo técnico, em um microscópio estereoscópio com aumento final de $50 \times$.

Foram considerados adequados para o cultivo in vitro os oócitos com três ou mais camadas de células do cumulus compactas, com citoplasma homogêneo ou apresentando pequenas irregularidades.

Os oócitos selecionados foram acondicionados em tubos plásticos de $1,5 \mathrm{ml}$ contendo meio Talp-Hepes e mantidos em estufa a $39^{\circ} \mathrm{C}$ até o momento do transporte para o laboratório de embriologia, realizado em câmara incubadora ${ }^{5}$ mantida à temperatura de $39^{\circ} \mathrm{C}$ em uma bolsa térmica. $\mathrm{O}$ tempo médio de transporte foi de 40

\footnotetext{
${ }^{3}$ Pluset, Serono

${ }^{4}$ Liquemine ${ }^{\circledR}$, Roche

${ }^{5}$ Modular Incubator Chamber, Billups-Rothenberg
}

minutos a uma hora.

Os oócitos foram submetidos à maturação in vitro em meio TCM-199 acrescido de $10 \%$ de soro de vaca em cio e $20 \mu \mathrm{g} / \mathrm{ml}$ de $\mathrm{FSH}$, por 22 horas, em estufa incubadora à $39^{\circ} \mathrm{C}$ com $5 \%$ de $\mathrm{CO}_{2}$ e $95 \%$ de umidade. Após a maturação, todos os oócitos foram fertilizados com sêmen congelado, de uma mesma partida, de um touro da raça Gir previamente selecionado. Para separação de espermatozóides vivos e mortos foi utilizado o método de swim up. A fecundação in vitro foi realizada em gotas de $100 \mu l$ de meio Fert-Talp acrescido de $10 \mu \mathrm{g} / \mathrm{ml}$ de heparina, cobertas com óleo mineral, com concentração espermática de $2,0 \times 10^{6}$ espermatozóides $/ \mathrm{ml}$ por um período aproximado de 22 horas (Parrish et al., 1986).

Os possíveis zigotos foram co-cultivados com células da granulosa em CR2aa (Moore e Bondioli, 1993) acrescido de $10 \%$ SBF, em gotas de $50 \mu$ l cobertas com óleo mineral. A avaliação da taxa de clivagem e a renovação do $50 \%$ do meio foram realizadas 72 horas pós-fecundação. A taxa de produção de blastocisto foi avaliada 192 horas pós-fecundação. Todas as etapas foram realizadas em estufa incubadora nas mesmas condições da maturação in vitro. Foram utilizados grupos de 10 a 30 oócitos por gota de fecundação/cultivo.

Os dados foram avaliados quanto ao atendimento das pressuposições da análise de variância (normalidade dos dados, aditividade, independência dos dados e homogeneidade de variâncias). Como a maioria das variáveis não atendeu a tais requisitos e não se conseguiu uma transformação adequada para os dados, procederam-se as análises usando-se testes estatísticos não paramétricos. Assim, as características número total de folículos, diâmetro do maior folículo e número de folículos grandes ( $\geq 9 \mathrm{~mm})$, médios (6 a $8 \mathrm{~mm}$ ) e pequenos $(\leq 5 \mathrm{~mm})$ foram analisadas utilizandose o teste de Wilcoxon, enquanto as taxas de recuperação e clivagem e de produção de blastocistos o foram pelo teste do qui-quadrado. A relação entre as características ovarianas e os oócitos classificados como viáveis foi determinada pelo método das correlações de Pearson. 


\section{RESULTADOS E DISCUSSÃO}

O protocolo que utilizou o pré-tratamento com FSH e a punção folicular uma vez por semana(PII) em vacas Gir aumentou $(\mathrm{P}<0,05)$ o número total de folículos, assim como o número de folículos grandes e médios $(\mathrm{P}<0,01)$ e o diâmetro do maior folículo $(\mathrm{P}<0,05)$ (Tab. 1). Os resultados concordam com os de outros autores que utilizaram protocolos similares em gado europeu (Gibbons et al., 1997; Goodhand et al., 1999; Sirard et al., 1999; Goodhand et al., 2000), e caracteriza a ação do FSH sobre o desenvolvimento folicular. Fricke et al. (1997) sugerem que o FSH exógeno superinduz o crescimento folicular em vacas por aumentar a proliferação de células da granulosa, aumentando a percentagem de folículos pequenos que se desenvolveram até folículos maiores, como observado no presente experimento Além disso, o FSH pode mudar o balanço entre folículos saudáveis e atrésicos, por prevenir ou retardar a atresia (Blondin et al., 1997). Então, o aumento do número de folículos observado no protocolo II pode ter ocorrido em razão do crescimento continuado de folículos que normalmente entrariam em atresia, e manutenção de uma taxa de proliferação de células foliculares relativamente alta.

Tabela 1. Número e classificação dos folículos ovarianos presentes no ovário e número total de oócitos recuperados (média \pm desvio padrão) por punção folicular, em vacas Gir, submetidas a dois protocolos $(\mathrm{P})$ de produção de embriões

\begin{tabular}{lcc}
\hline Tratamento & PI & PII \\
\hline Total de folículos & $13,63 \pm 5,85 \mathrm{a}$ & $20,36 \pm 9,45 \mathrm{~b}$ \\
Diâmetro do maior folículo & $10,53 \pm 2,89 \mathrm{a}$ & $13,84 \pm 3,45 \mathrm{~b}$ \\
Folículos com $\geq 9 \mathrm{~mm}$ & $1,03 \pm 0,96 \mathrm{a}$ & $6,84 \pm 4,34 \mathrm{~b}$ \\
Folículos de 6 a $8 \mathrm{~mm}$ & $4,00 \pm 2,56 \mathrm{a}$ & $10,52 \pm 6,70 \mathrm{~b}$ \\
Folículos com $\leq 5 \mathrm{~mm}$ & $8,23 \pm 5,70 \mathrm{a}$ & $3,00 \pm 3,68 \mathrm{~b}$ \\
Total de oócitos recuperados/ sessão & $9,73 \pm 8,13 \mathrm{a}$ & $10,68 \pm 6,50 \mathrm{a}$ \\
\hline
\end{tabular}

Médias seguidas por letras distintas diferem entre si $(\mathrm{P}<0,05)$, pelo teste de Wilcoxon.

Apesar de alguns autores relatarem que a utilização de FSH antes da punção aumenta o número de oócitos recuperados (Merton et al., 2003), no presente experimento isso não ocorreu $(\mathrm{P}>0,05)$, não havendo diferença no núnero de oócitos recuperados por sessão de punção (Tab. 1) e taxa de recuperação (Tab. 2) entre os protocolos. Looney et al. (1994) também não observaram melhoria na taxa de recuperação de oócitos utilizando um protocolo similar. Ao contrário, existem afirmações de que a terapia gonadotrófica promove diminuição na recuperação de oócitos (Goodhand et al., 1996; 1999; Sirard et al., 1999). Relata-se relação inversa entre o diâmetro folicular e a taxa de recuperação oocitária (Seneda et al., 2001), confirmada pelos resultados do presente experimento, em que se observou correlação positiva entre o número de folículos pequenos e o total de oócitos recuperados (Tab. 3).

Tabela 2. Taxas de clivagem e de produção de blastocistos de oócitos recuperados in vivo em vacas Gir submetidas a dois protocolos $(\mathrm{P})$ de produção de embriões

\begin{tabular}{lcccccc}
\hline & \multicolumn{2}{c}{ PI } & & \multicolumn{2}{c}{ PII } \\
\cline { 2 - 3 } \cline { 5 - 6 } & $\mathrm{n}$ & $\%$ & & $\mathrm{n}$ & $\%$ \\
\hline Taxa de recuperação & 292 & 71,39 & & 267 & 67,09 \\
Taxa de clivagem & 90 & $44,78 \mathrm{a}$ & & 93 & $56,02 \mathrm{a}$ \\
Taxa de produção de & 23 & $11,44 \mathrm{a}$ & & 30 & $18,07 \mathrm{a}$ \\
blastocisto & 201 & & & 166 \\
Total de oócitos cultivados & 201 & & \\
Percentagens seguidas por letras distintas na & linha & diferem \\
entre si $(\mathrm{P}<0,05)$ pelo teste do qui-quadrado.
\end{tabular}


Tabela 3. Matriz de correlação entre características ovarianas e número de COCs classificados com graus I e II e total de oócitos recuperados

\begin{tabular}{|c|c|c|c|c|c|c|}
\hline & $\begin{array}{l}\text { Folículos } \\
\geq 9 \mathrm{~mm}\end{array}$ & $\begin{array}{c}\text { Folículos } \\
\text { de } 6 \text { a } 8 \mathrm{~mm}\end{array}$ & $\begin{array}{c}\text { Folículos } \\
\leq 5 \mathrm{~mm}\end{array}$ & $\begin{array}{l}\text { COCs } \\
\text { grauI }\end{array}$ & $\begin{array}{l}\text { COCs } \\
\text { grauII }\end{array}$ & $\begin{array}{l}\text { Total de oócitos } \\
\text { recuperados }\end{array}$ \\
\hline Folículos $\geq 9 \mathrm{~mm}$ & & $\begin{array}{c}* * * 0,60 \\
(\mathrm{n}=55)\end{array}$ & $\begin{array}{c}*_{-}-0,46 \\
(\mathrm{n}=55)\end{array}$ & $\begin{array}{c}* * * 0,60 \\
(\mathrm{n}=55)\end{array}$ & $\begin{array}{l}-0,06 \\
(\mathrm{n}=55)\end{array}$ & $\begin{array}{c}0,14 \\
(\mathrm{n}=55)\end{array}$ \\
\hline $\begin{array}{l}\text { Folículos } \\
\text { entre } 6 \text { e } 8 \mathrm{~mm}\end{array}$ & & & $\begin{array}{l}-0,26 \\
(\mathrm{n}=55)\end{array}$ & $\begin{array}{c}* * * 0,67 \\
(\mathrm{n}=55)\end{array}$ & $\begin{array}{c}0,13 \\
(n=55)\end{array}$ & $\begin{array}{l}* 0,36 \\
(\mathrm{n}=55)\end{array}$ \\
\hline Folículos $\leq 5 \mathrm{~mm}$ & & & & $\begin{array}{l}-0,07 \\
(\mathrm{n}=55)\end{array}$ & $\begin{array}{c}* * * 0,55 \\
(\mathrm{n}=55)\end{array}$ & $\begin{array}{c}* * * 0,51 \\
(\mathrm{n}=55)\end{array}$ \\
\hline COCs grau I & & & & & $\begin{array}{c}* 0,33 \\
(\mathrm{n}=55)\end{array}$ & $\begin{array}{c}* * * 0,60 \\
(\mathrm{n}=55)\end{array}$ \\
\hline COCs grau II & & & & & & $\begin{array}{c}* * * 0,91 \\
(\mathrm{n}=55) \\
\mathrm{n}\end{array}$ \\
\hline
\end{tabular}

***(P<0,0001); **P $<0,001 ; * \mathrm{P}<0,02$.

Apesar de folículos maiores serem tecnicamente mais fáceis de aspirar que os pequenos, eles não necessariamente produzem oócitos. Um dos motivos do aumento no número de folículos não ter sido acompanhado pela melhora da taxa de recuperação de oócitos pode ser a consistência do fluido folicular. Folículos grandes, tais como os estimulados por gonadotropinas exógenas podem estar mais maduros e conter aglomerados de células da granulosa e fluido folicular mais viscoso, enquanto folículos pequenos não possuem fluido folicular viscoso e apresentam grumos menores de células (Goodhand et al., 1999). Conseqüentemente, a pressão de vácuo de $80 \mathrm{mmHg}$ utilizada pode não ter sido elevada o suficiente para aspirar o fluido viscoso dos folículos $>9 \mathrm{~mm}$ FSH estimulados. Em adição, um colapso da parede do folículo ao redor da agulha pode impedir o fluxo do aspirado ou encarcerar o oócito (Goodhand et al., 1999). O uso de uma agulha de diâmetro maior e/ou uma pressão de vácuo elevada poderia aumentar a recuperação dos oócitos, embora o aumento da pressão pudesse ocasionar um efeito deletério na qualidade dos oócitos (Manik et al., 2003).

Dificuldades na realização das aspirações têm sido associadas ao aumento progressivo no tamanho dos ovários pelo acúmulo de tecido luteal formado pela luteinização parcial dos folículos aspirados, em animais pré-estimulados antes da coleta (Stubbings e Walton, 1995). Entretanto, tal dificuldade não ocorreu no presente experimento, pois o uso dos implantes de norgestomet reduziu a luteinização nos folículos puncionados.

O número de oócitos recuperados por sessão de punção teve uma variação muito grande entre os animais, tanto no protocolo I como no II (1 a 38), o que evidencia diferenças no potencial das vacas utilizadas como doadoras de oócitos. Tal fato torna necessária a avaliação prévia do animal antes de sua utilização em programas comerciais de PIVE. As razões para essa variabilidade ainda são pouco compreendidas.

Oócitos de melhor qualidade foram obtidos no protocolo II (Tab. 4), com maior percentagem de oócitos classificados como de grau I e menor de oócitos degenerados $(\mathrm{P}<0,05)$. Resultados semelhantes foram observados por Blondin et al. (1996), Goodhand et al. (1999), Roth et al. (2002) e Faber et al. (2003).

Tabela 4. Classificação dos oócitos recuperados em vacas Gir submetidas a dois protocolos $(\mathrm{P})$ de produção de embriões

\begin{tabular}{lccccc}
\hline \multirow{2}{*}{ Classificação dos oócitos } & \multicolumn{2}{c}{ PI } & & \multicolumn{2}{c}{ PII } \\
\cline { 2 - 3 } \cline { 5 - 6 } & $\mathrm{n}$ & $\%$ & & $\mathrm{n}$ & $\%$ \\
\hline Grau I & 55 & $18,84 \mathrm{a}$ & & 113 & $42,32 \mathrm{~b}$ \\
Grau II & 169 & $57,88 \mathrm{~b}$ & & 124 & $46,44 \mathrm{a}$ \\
Parcialmente desnudos & 18 & $6,16 \mathrm{a}$ & & 12 & $4,50 \mathrm{a}$ \\
Desnudos e/ou degenerados & 28 & $9,60 \mathrm{a}$ & & 8 & $3,00 \mathrm{~b}$ \\
Expandidos & 16 & $5,48 \mathrm{a}$ & & 9 & $3,37 \mathrm{a}$ \\
Zona pelúcida & 6 & 2,05 & & 1 & 0,37 \\
Total & 292 & & & 267 & \\
\hline
\end{tabular}

Percentagens seguidas por letras distintas diferem entre si $(\mathrm{P}<0,01)$ pelo teste do qui-quadrado. 
Apesar da morfologia do cumulus não permitir a discriminação entre oócitos competentes e incompetentes, a remoção artificial das células do cumulus demonstra que a presença dessas células é necessária para a maioria dos oócitos expressar a competência (Leibfried-Rutledge et al., 1989). A espessura do cumulus varia de acordo com a "saúde" e o tamanho dos folículos. Um número reduzido de camadas pode ser conseqüência de oócitos aspirados de folículos em atresia (Sirard e Blondin, 1996). Além disso, folículos com maior diâmetro permitem a aspiração de maior volume de líquido durante a punção, o que reduz a ocorrência de turbulências dentro do circuito (Horne et al., 1996), evitando a perda de células decorrente do sistema de aspiração. Observou-se associação positiva entre o número de folículos de tamanho grande e médios e o número de COCs do grau I (Tab. 3). Assim, o uso de FSH pode ter melhorado a qualidade morfológica dos oócitos por diminuir a população de folículos atrésicos (Blondin et al., 1996) e aumentar o diâmetro folicular.

A taxa de clivagem foi maior $(\mathrm{P}<0,05)$ para o protocolo II, entretanto não houve aumento $(\mathrm{P}=0,072)$ na taxa de produção de embriões (Tab. 2). Alguns autores sugeriram que o FSH beneficia o desenvolvimento embrionário por sincronizar a população folicular, adiantando o desenvolvimento dos folículos e iniciando a maturação in vivo do oócitos, o que levaria a um aumento da competência de desenvolvimento oocitária antes da recuperação dos mesmos (Gibbons et al., 1994). Além disso, o uso do FSH pode alterar o ambiente folicular ao redor do oócito, influenciando direta ou indiretamente a qualidade do oócito (Roth et al., 2002). O FSH exógeno aumenta a densidade de receptores de IGF-1 (Spicer et al., 1994) e diminui a quantidade de proteínas ligadoras de IGF -2 (IGFBP-2) em folículos bovinos (Echternkamp et al., 1994). Assim, o maior desenvolvimento folicular e o aumento na biodisponibilidade e bioatividade do IGF-1 FSH-induzidos poderiam estar associados à maior taxa de clivagem observada nos oócitos provenientes do protocolo II. Embora o estádio de blastocisto não garanta desenvolvimento posterior, é um potente indicador da competência de desenvolvimento inicial (McEvoy et al., 2000). A terapia gonadotrófica utilizando o FSH melhorou a taxa de prenhez segundo Faber et al. (2003), mas no presente experimento não foi possível avaliar essa característica.

Outros autores não observaram efeito benéfico do pré-estímulo com FSH antes da punção folicular para PIVE (Blondin et al., 1996). Greve et al. (1995) sugeriram que a superestimulação ovariana com FSH prejudica a competência do oócito por alterar a duração da fase folicular. Postula-se que a estimulação hormonal possa desacoplar a maturação do folículo e do oócito (Blondin et al., 1996) e causar uma assincronia entre a maturação nuclear e citoplasmática dos oócitos (Bousquet et al., 1995), levando a um distúrbio no desenvolvimento oocitário. Seneda et al. (2003) não encontraram diferenças na avaliação ultra-estrutural entre oócitos provenientes de folículos grandes ou pequenos, após a aplicação de FSH.

O efeito do FSH no desenvolvimento embrionário pode ser influenciado pelo modo de administração e pela freqüência de aspiração. Múltiplas doses de FSH e aspiração de animais estimulados uma vez por semana têm sido mais eficientes que uma simples administração e punções em intervalos menores (Goodhand et al., 1996), similar ao protocolo utilizado neste experimento. Além disso, taxas de clivagem baixas podem ser resultado da não seleção dos oócitos antes da fertilização ou pela utilização de sistemas de cultivo in vitro diferentes (Looney et al., 1994).

\section{CONCLUSÃO}

A pré-estimulação ovariana com FSH antes da punção folicular pode melhorar a qualidade e a taxa de clivagem dos oócitos recuperados em vacas Gir.

\section{REFERÊNCIAS BIBLIOGRÁFICAS}

BLONDIN, P.; COENEN, K.; GUIBAULT, L.A. et al. Superovulation can reduce the developmental competence of bovine embryos. Theriogenology, v.46, p.1191-1203, 1996.

BOUSQUET, T.D.; MILOVANOV, C.; BELL, J.C. et al. Nuclear and citoplasmic maturation of oocyte aspirated from large follicles in superovulated heifers. Theriogenology, v.43, p.172, 1995.

ECHTERNKAMP, S.E.; HOWARD, H.J., ROBERTS, A.J. et al. Relationships among concentrations o steroids, insulin- 
like growth factor-I and insulin-like binding proteins in ovarian follicular fluid of beef cattle. Biol. Reprod., v. 51, p.971-981, 1994.

FABER, D.C.; MOLINA, J.A.; OHLRICHS, C.L. et al. Commercialization of animal biotechnology. Theriogenology, v.59, p.125-138, 2003.

FAIR, T.; HYTTEL, P.; GREVE, T. Bovine oocyte diameter in relation to maturational competence and transcriptional activity. Mol. Reprod. Develop., v.42, p.437-442, 1995.

FREITAS, C.; SÁ, W.F. FERREIRA, A.M. et al. Produção de embriões em doadoras Gir utilizando doses reduzidas de FSH - Resultados preliminares. Arq. Fac. Vet. UFRGS, v.26 (supl.), p.272, 1998.

FRICKE, P.M.; AL-HASSAN, M.J.; ROBERTS, A.J. et al. Effects of gonadotropin treatment on size, number and cell proliferation of antral follicles in cows. Dom. Anim. Endocrinol., v.14, p.171-180, 1997.

GIBBONS, J.R.; BEAL, W.E.; KRISHER, R.L. et al. Effect of once versus twice-weekly transvaginal follicular aspiration on bovine oocyte recovery and embryo development. Theriogenology, v.42, p.405-419, 1994.

GIBBONS, J.R.; WILTBANK, M.C.; GINTHER, O.J. Functional interrelationships between follicles greater than 4 $\mathrm{mm}$ and the follicle-stimulating hormone surge in heifers. Biol. Reprod., v.57, p.1066-1073, 1997.

GOODHAND, K.L.; BROADBENT, P.J.; HUTCHINSON, J.J.M. et al. In vivo oocyte recovery and in vitro embryo production in cattle pre-treated with $\mathrm{FSH}$, progestogen and oestradiol. Theriogenology, v.45, p.355, 1996.

GOODHAND, K.L.; STAINS, M.E.; HUTCHINSON, J.S.M. et al. In vivo oocyte recovery and in vitro embryo production from bovine treated with progesterone, oestradiol and FSH. Anim. Reprod. Sci., v.63, p.145-158, 2000.

GOODHAND, K.L.; WATT, R.G.; STAINES, M.E. et al. In vivo recovery and in vitro embryo production from bovine donors aspirated at different frequencies or following FSH treatment. Theriogenology, v.51, p.951-961, 1999.

GREVE, T.; CALLESEN, H.; HYTTEL, P. et al. The effect of exogenous gonadotropins on oocyte and embryo quality in cattle. Theriogenology, v.43, p.41-50, 1995.

HORNE, R.; BISHOP, C.J.; REEVES, G. et al. Aspiration of oocytes for in vitro fertilization. Human Reprod. Update, v.2, p.77-85, 1996.

LEIBFRIED-RUTLEDGE， M.L.; CRITSER, E.S.; PARRISH, J.J. et al. In vitro maturation and fertilization of bovine oocytes. Theriogenology, v.31, p.61-71, 1989.

LOONEY, C.R.; LINDSEY, B.R.; GONSETH, C.L. et al. Commercial aspects of oocyte retrieval and in vitro fertilization (IVF) for embryo production in problems cows. Theriogenology, v.41, p.67-72, 1994.

MANIK, R.S.; SINGLA, S.K.; PALTA, P. Collection of oocyte through transvaginal ultrasound-guided aspiration of follicles in an Indian breed of cattle. Anim. Reprod. Sci., v.76, p.155-161, 2003.

McEVOY, T.G.; SINCLAIR, K.D.; YOUNG, L.E. et al. Large offspring syndrome and other consequences of ruminant embryo culture in vitro. Human Fertil., v.3, p.238246, 2000.

MERTON, J.S.; de ROOS, A.P.W.; MULLAART, E. et al. Factors affecting oocyte quality and quantity in commercial application of embryo technologies in the cattle breeding industry. Theriogenology, v.59, p.651-667, 2003.

MOORE, K.; BONDIOLI, K.R. Glicine and alanine supplementation of culture medium enhances development of in vitro matured and fertilized cattle embryo. Biol. Reprod., v.48, p.833-840, 1993.

PARRISH， J.J.; SUSKO-PARRISH， J.L.; LEIBFRIEDRUTLEDGE, M.L.; et al. Bovine in vitro fertilization with frozen-thawed semen. Theriogenology, v.25, p.591-600, 1986.

PAVLOK, A.; LUCAS-HAHN, A.; NIEMANN, H. Fertilization and developmental competence of bovine oocyte derived from different categories of antral follicles. Mol. Reprod. Devel., v.31, p.63-67, 1992.

ROTH, Z.; ARAV, A.; BRAW-TAL, R. et al. Effect of treatment with follicle-stimulating hormone or bovine somatotropin on the quality of oocyte aspirated in the autumn from previously heat-stressed cows. J. Dairy Sci., v.85, p.1398-1405, 2002.

SENEDA, M.M.; ESPER, C.R.; GARCIA, J.M. et al. Avaliação de oócitos bovinos obtidos após utilização do FSH pela microscopia eletrônica de transmissão. Acta Sci. Vet., v.31, supl., p.564, 2003.

SENEDA, M.M.; ESPER, C.R.; GARCIA, J.M. et al. Relationship between follicle size and ultrasound-guided transvaginal oocyte recovery. Anim. Reprod. Sci., v.67, p.3743, 2001 .

SIRARD, M.A.; BLONDIN, P. Oocyte maturation and IVF in cattle. Anim. Reprod. Sci., v.42, p.417-426, 1996.

SIRARD, M.A.; PICARD, L.; DERY, M. et al. The time interval between FSH administration and ovarian aspiration influences the developmental of cattle oocyte. Theriogenology, v.51, p.699-708, 1999.

SPICER, L.J.; ALPIZAR, A.; VERNON, R.K. Insulin-like growth factor-I receptors in ovarian granulosa cells: effects of follicular size and hormones. Mol. Cell. Endocrinol., v.102, p.69-76, 1994.

STUBBING, R.B.; WALTON, J.S. Effects of ultrasonically guided follicle aspiratin on estrous cycle and follicular dynamics in Holstein cows. Theriogenol., v.43, p.705-712, 1995.

WHITTINGAM, D.G. Culture of mouse ova. J. Reprod. Fertil., v.14, p.7-21, 1971. 